\title{
Microstructure Evolution Mechanism in Iron Aluminides/CrMo Steel Composite Prepared by Solid State Bonding
}

\author{
Naoya MASAHASHI and Shuji HANADA \\ Institute for Materials Research, Tohoku University, 2-1-1 Katahira, Aoba, Sendai 980-8577 Japan. \\ E-mail: masahasi@imr.tohoku.ac.jp, hanada@imr.tohoku.ac.jp
}

(Received on August 28, 2003; accepted in final form on February 4, 2004)

\begin{abstract}
This work addresses a mechanism of columnar microstructure evolution during diffusion bonding in a composite of iron aluminide and CrMo steel focusing on the role of alloying on microstructure. Columnar microstructure develops in the steel side of diffusion couples of iron aluminide and $\mathrm{Fe}-\mathrm{X}(\mathrm{X}=\mathrm{Cr}$, Mo) steel, when the steel composition is in the gamma phase at the bonding temperature. This is consistent with the proposed model for columnar microstructure evolution, which contributes to bonding strength between iron aluminide and steel. Interdiffusion coefficient at the Matano interface decreases with increasing the concentration of alloying elements in steel, and its decrease rate is higher for Mo than for Cr. The columnar grains in the steel side of the couple are longer than expected by chemical composition analysis, and their lengths increase with the interdiffusion coefficient. Microstructure evolution mechanism is discussed in terms of the kinetics of nucleation and subsequent grain growth during diffusion bonding.
\end{abstract}

KEY WORDS: microstructure evolution; iron aluminide; transformation; diffusion; solid state bonding; composite.

\section{Introduction}

Iron-aluminum alloys exhibit high oxidation resistance, which is due to formation of stable and protective $\alpha-\mathrm{Al}_{2} \mathrm{O}_{3}$ layer on the surface at higher temperatures than $1173 \mathrm{~K}$ at low oxygen partial pressures such as $10^{-17} \mathrm{~Pa}^{1)}$ Chemically stable $\alpha-\mathrm{Al}_{2} \mathrm{O}_{3}$ (melting point $2375 \mathrm{~K}$ ) is formed by polymorphic transformation from various forms of $\mathrm{Al}_{2} \mathrm{O}_{3}$ such as $\theta, \gamma$ at temperatures higher than $1273 \mathrm{~K}^{2-5)}$ The stable layer is formed when the aluminum content in the alloy exceeds 14 at $\%{ }^{1,6)}$ The authors have proposed a corrosion resistant composite of iron aluminide and steel, expecting an alternative material for corrosion-resistant alloys. ${ }^{7-8)}$ The advantages of this composite include lightweight and high strength, which can be optimized by the aluminum content of the composite. As the first trial, a heat resistant CrMo steel was clad rolled on an iron aluminide sheet to form a composite, which demonstrates high bonding strength due to a sufficient interdiffusion of the constituents, and an improvement of oxidation resistance of the steel due to $\mathrm{Al}$ diffusion. ${ }^{8)}$ Microstructure of the composite depends on the bonding condition, and influences the bonding strength between iron aluminide alloy and steel. In a previous study using diffusion couples of iron aluminide with chromium and pure iron, ${ }^{7)}$ it is reported that the transformation temperature determined by differential thermal analysis (DTA) is well correlated with the microstructure of the iron side in the couple. When the bonding temperature is higher than alpha-gamma transformation temperature (described as $\mathrm{A}_{3}$ ), columnar microstructure evolved from the joint inter- face into pure iron, and the composite exhibits high bonding strength. In addition, water quenching from bonding temperatures above $\mathrm{A}_{3}$ lead to columnar microstructure, and the length of columnar grains increased with bonding time and temperature. These prove that the columnar microstructure is formed in the retention stage (not in the cooling stage), and the columnar microstructure evolution could be regarded as a diffusion controlled phenomena. From these results and the reported $\mathrm{Ti}-\mathrm{Al}-\mathrm{Cr}$ ternary phase diagram, ${ }^{9)}$ the mechanism of the columnar microstructure evolution is understood in terms of the transformation in the steel from gamma to alpha, which is caused by aluminum diffusion from iron aluminide to the steel during diffusion bonding. ${ }^{8)}$ Nucleated alpha grains at the interface grow into steel matrix due to the difference of the aluminum concentration between the two materials. This is illustrated schematically in Fig. 1. According to this model, it is plausible that the length of columnar grains corresponds to the distance of aluminum diffusion. However, the experimental results of the composite of iron aluminide and CrMo steel revealed that the length of columnar grains was longer than the distance between the joint interface and the position where the aluminum concentration equals to zero. ${ }^{8)}$ In this paper, the effect of alloying in steel on the formation of columnar microstructure will be discussed and the proposed mechanism of microstructure formation in the composite is reexamined. The microstructures and properties of the composite of iron aluminide with various compositions and CrMo steel will be separately reported. 


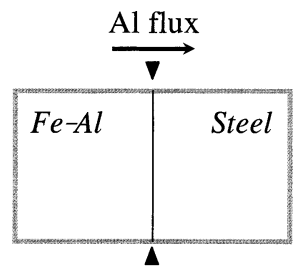

Al diffusion into steel

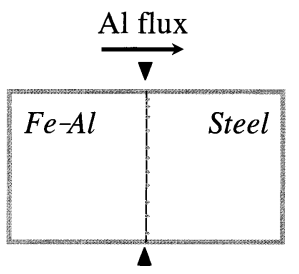

$\alpha$ nucleation at interface

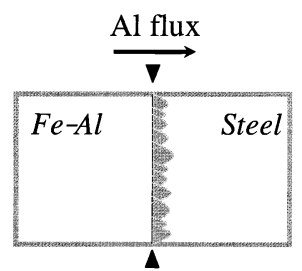

Grain growth into steel

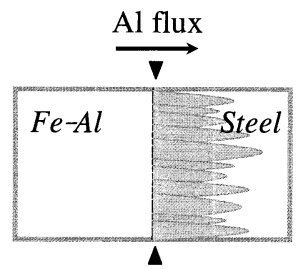

Columnar grain evolution

Fig. 1. Schematic illustration of the mechanism for columnar microstructure evolution during solid state bonding.
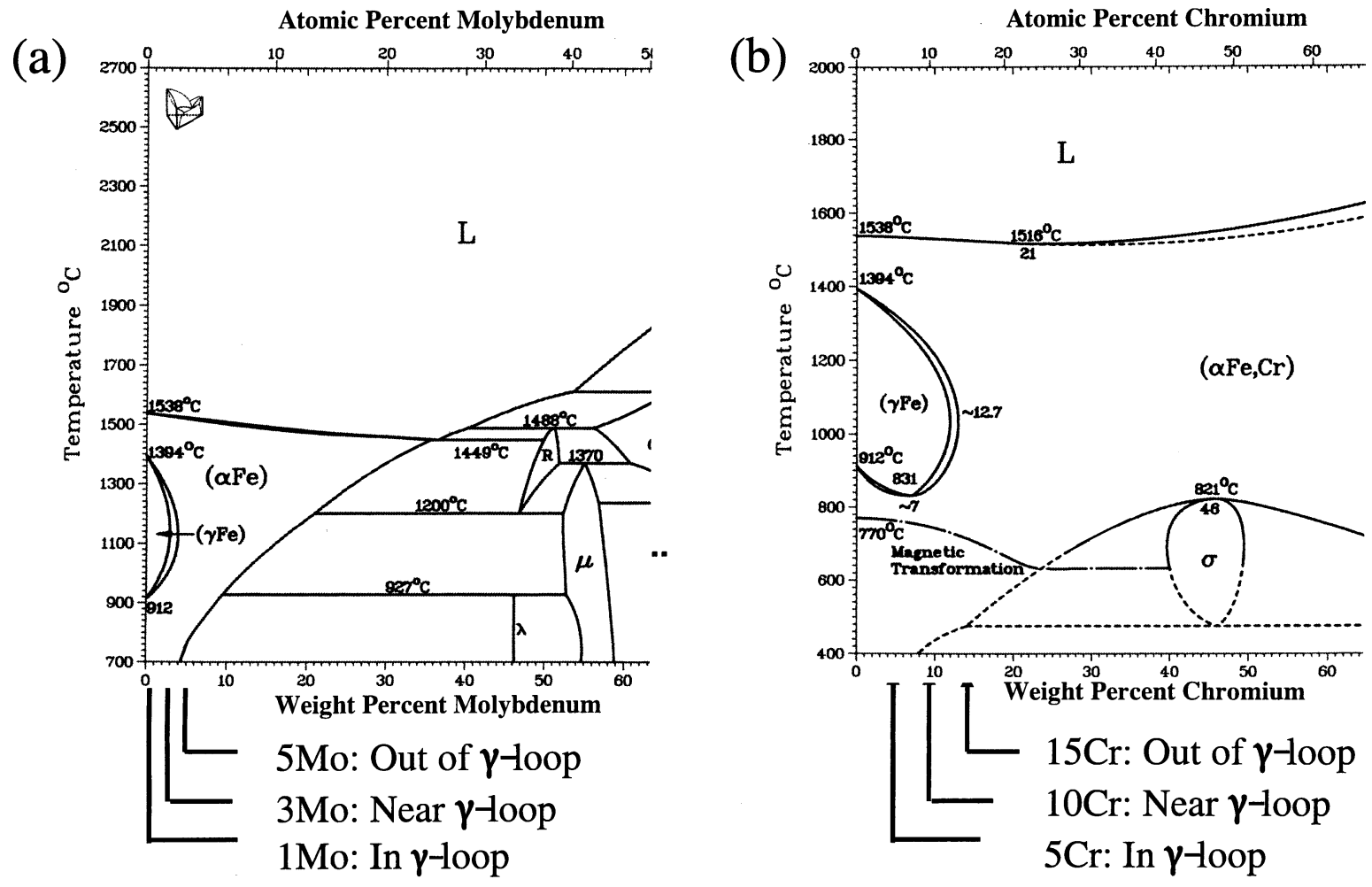

Fig. 2. Fe rich portions of binary phase diagrams; (a) Fe-Mo and (b) $\mathrm{Fe}-\mathrm{Cr}$.

\section{Experimental Procedure}

The composition of iron aluminide alloy is $\mathrm{Fe}-28 \mathrm{at} \% \mathrm{Al}$ (to be abbreviated as 28Al hereafter) instead of $\mathrm{Fe}$ 28 at $\% \mathrm{Al}-6$ at $\% \mathrm{Cr}(6 \mathrm{Cr})$ used in the previous works, ${ }^{7,8)}$ because iron aluminide without chromium is preferable to investigate the influence of alloying elements in steel on microstructure formation. As the steels for composite, $\mathrm{Fe}-1$, 3, 5at\%Mo (1Mo, 3Mo and 5Mo) and $\mathrm{Fe}-5,10,15 \mathrm{at} \% \mathrm{Cr}$ $(5 \mathrm{Cr}, 10 \mathrm{Cr}$ and $15 \mathrm{Cr}$ ) were selected. Figures 2 (a) and 2 (b) represent the iron rich portions of $\mathrm{Fe}-\mathrm{Mo}$ and $\mathrm{Fe}-\mathrm{Cr}$ binary phase diagrams, ${ }^{10)}$ respectively. They reveal gamma loops with 2.1 at $\%$ at $1423 \mathrm{~K}$ for Fe-Mo and 11.9 at $\%$ at $1323 \mathrm{~K}$ for $\mathrm{Fe}-\mathrm{Cr}$ as solubility limit. The alloy compositions of steel were selected as in-gamma loop alloys (1Mo and $5 \mathrm{Cr}$ ), near gamma loop alloys (3Mo and $10 \mathrm{Cr}$ ) and out of gamma loop alloys (5Mo and $15 \mathrm{Cr}$ ). In addition, a CrMo steel with composition of $\mathrm{Fe}-5 \mathrm{wt} \% \mathrm{Cr}-0.5 \mathrm{wt} \% \mathrm{Mo}(\mathrm{CrMo})$ and pure iron were prepared as references. All samples were prepared by argon arc melting, followed by cold rolling for steel and hot rolling at $1273 \mathrm{~K}$ for iron aluminide to about $5 \mathrm{~mm}$ in thickness with about $60 \%$ reduction. The microstructures of iron aluminide are equi-axed with coarse grains of about $300 \mu \mathrm{m}$, whereas those of steel exhibit deformed structure. Table 1 summarizes the chemical analysis results of samples, showing little difference between the nominal and analyzed compositions. Specimens of $5 \times 10 \times$ $10 \mathrm{~mm}^{3}$ were prepared from the rolled plates and its contact surface for bonding was ground with 1500 grade $\mathrm{SiC}$ paper and $1.0 \mu \mathrm{m}$ alumina particles. Polished specimens were cleaned by an ultrasonic apparatus in acetone and clamped by alumina jigs. Diffusion bonding was conducted for $172.8 \mathrm{ks}$ at $1323 \mathrm{~K}$ in a vacuum of less than $2 \times 10^{-3} \mathrm{~Pa}$. Hereafter, the bonded sample will be described as $28 \mathrm{Al} / 1 \mathrm{Mo}$ for a couple of $28 \mathrm{Al}$ and $1 \mathrm{Mo}$. A bonded sample was cut into two pieces perpendicular to the joint interface. The cut surface was polished mechanically, followed by chemical polishing by using colloidal silica suspension with a particle size of approximately $0.04 \mu \mathrm{m}$. This piece was supplied for EBSP (electron backscatter patterns) and SEM-EDS analysis. Orientation measurements were carried out with a step size of $1-10 \mu \mathrm{m}$ using OIM (Orientation Imaging Microscopy) developed by TexSEM Laboratories, linked with a Phillips XL 30 FEG SEM. 
Table 1. Summary of chemically analyzed compositions.

\begin{tabular}{c|ccccccc}
\hline & Fe at. \% & $\mathrm{Al}$ at. \% & Cr at. \% & Mo at. \% & O wt. \% & N wt. \% & C wt. \% \\
\hline $5 \mathrm{Cr}$ & 94.7 & - & 5.3 & - & 0.0111 & 0.0006 & 0.00011 \\
$10 \mathrm{Cr}$ & 89.4 & - & 10.6 & - & 0.0109 & 0.0004 & 0.00008 \\
$15 \mathrm{Cr}$ & 84.2 & - & 15.8 & - & 0.0130 & 0.0004 & 0.00010 \\
$1 \mathrm{Mo}$ & 99.0 & - & - & 1.00 & 0.0153 & 0.0006 & 0.00016 \\
$3 \mathrm{Mo}$ & 97.0 & - & - & 2.97 & 0.0212 & 0.0007 & 0.00025 \\
$5 \mathrm{Mo}$ & 95.0 & - & - & 4.93 & 0.0463 & 0.0079 & 0.00014 \\
$\mathrm{CrMo}$ & 94.3 & - & 5.4 & 0.29 & 0.0341 & 0.0002 & 0.00003 \\
$\mathrm{Fe}$ & 99.9 & - & - & - & -0.0073 & 0.0002 & 0.00009 \\
$28 \mathrm{Al}$ & 72.4 & 27.7 & - & - & -0.0036 & 0.0029 & 0.00135 \\
\hline
\end{tabular}
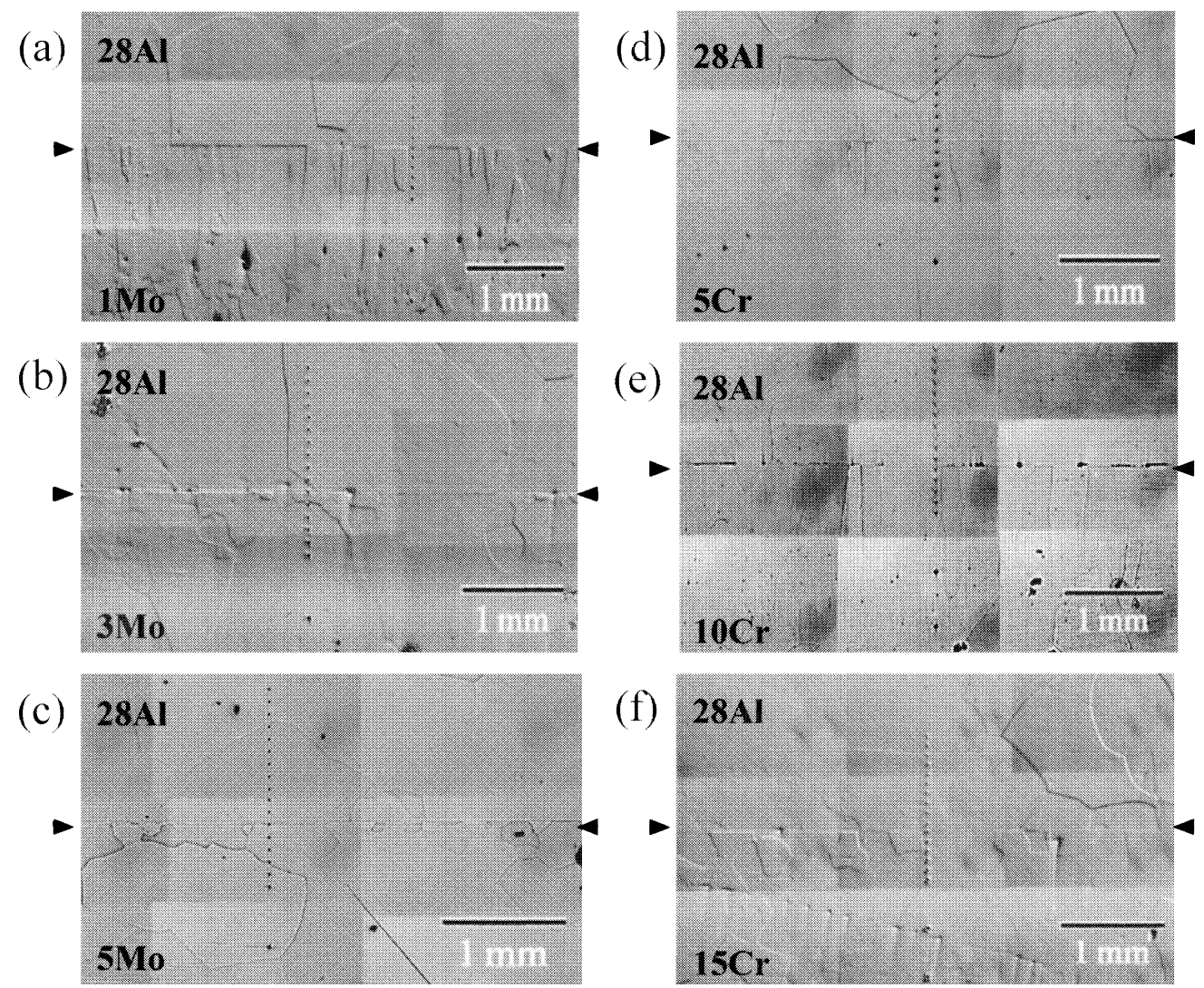

Fig. 3. Optical microscopy images from the cross section close to the geometric center of samples (a) $28 \mathrm{Al} / 1 \mathrm{Mo}$, (b) $28 \mathrm{Al} / 3 \mathrm{Mo}$, (c) $28 \mathrm{Al} / 5 \mathrm{Mo}$, (d) $28 \mathrm{Al} / 5 \mathrm{Cr}$, (e) $28 \mathrm{Al} / 10 \mathrm{Cr}$ and (f) $28 \mathrm{Al} / 15 \mathrm{Cr}$.

\section{Results and Discussion}

\subsection{Microstructure Evolution}

Figures 3(a)-3(f) show the microstructures of 28Al/1Mo, $28 \mathrm{Al} / 3 \mathrm{Mo}, 28 \mathrm{Al} / 5 \mathrm{Mo}, 28 \mathrm{Al} / 5 \mathrm{Cr}, 28 \mathrm{Al} / 10 \mathrm{Cr}$ and $28 \mathrm{Al} /$ $15 \mathrm{Cr}$, respectively. Columnar microstructure is observed in the steel side of $28 \mathrm{Al} / 1 \mathrm{Mo}, 28 \mathrm{Al} / 5 \mathrm{Cr}$ and $28 \mathrm{Al} / 10 \mathrm{Cr}$; these steels in the couples have the in-gamma loop compositions. On the other hand, equiaxed microstructure is observed in the steel side of $28 \mathrm{Al} / 3 \mathrm{Mo}, 28 \mathrm{Al} / 5 \mathrm{Mo}$, and $28 \mathrm{Al} / 15 \mathrm{Cr}$; the compositions of steels in the couples are of the out-ofgamma loop type. Coarse grains with about $300 \mu \mathrm{m}$ are found in the iron aluminide side of all samples, which is almost similar to pre-bonding microstructure. Figure 4 displays the orientation of crystallite lattice plane aligned with the surface (described as ND) of the same sample as Fig. 3, showing that columnar microstructure is clearly found in
$28 \mathrm{Al} / 1 \mathrm{Mo}, 28 \mathrm{Al} / 5 \mathrm{Cr}$ and $28 \mathrm{Al} / 10 \mathrm{Cr}$. Neither preferred orientation of the columnar grains nor particular orientation relationship between neighboring grains is recognized in all samples from OIM analysis, which is the same with $6 \mathrm{Cr} / \mathrm{Fe}^{7)}$ and $6 \mathrm{Cr} / \mathrm{CrMo}{ }^{8)}$ In the proposed model to explain columnar microstructure evolution, ${ }^{7,8)}$ transformation caused by aluminum diffusion from iron aluminide to steel is required. When the steel composition is within or out of gamma loop, transformation from alpha to gamma should or not occur during diffusion bonding, respectively. The present results in Figs. 3 and 4 support the proposed model.

Figure 5 displays optical microstructures and orientation images for $\mathrm{ND}$ of $28 \mathrm{Al} / \mathrm{Fe}$ and $28 \mathrm{Al} / \mathrm{CrMo}$, showing columnar microstructure in $\mathrm{Fe}$ and CrMo side of respective couples. Microstructural characteristics of the columnar grains for the investigated couples with references to $28 \mathrm{Al} /$ $\mathrm{Fe}$ and $28 \mathrm{Al} / \mathrm{CrMo}$ are summarized in Table 2 . Individual 
(a)

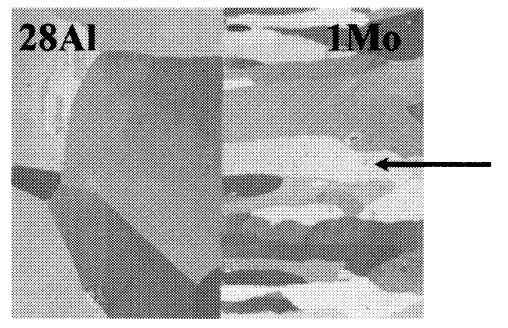

(b)

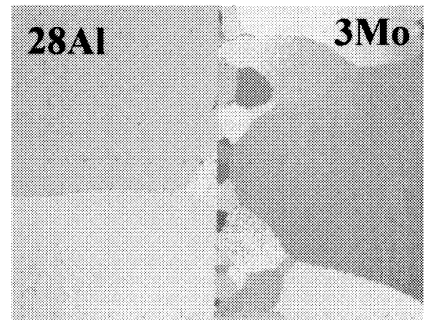

(c)

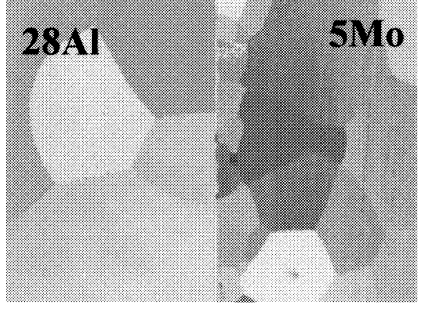

(d)

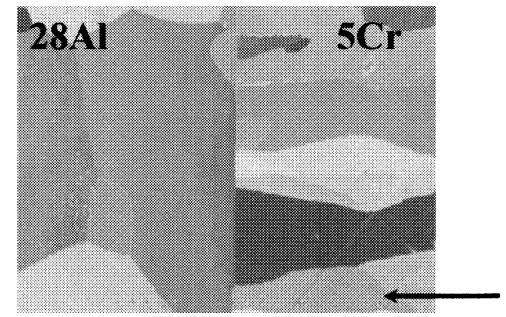

(e)

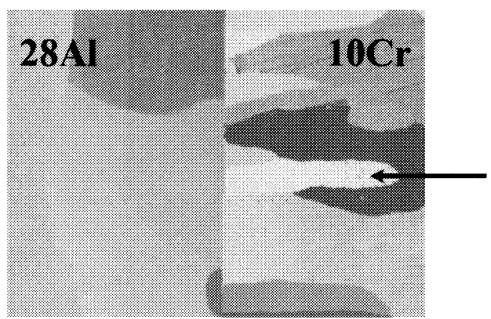

(f)

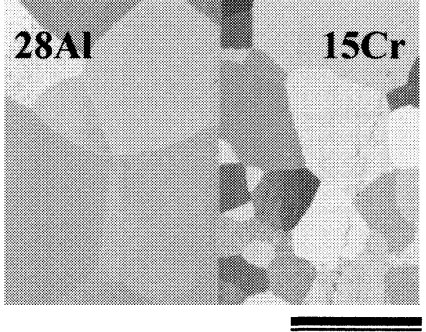

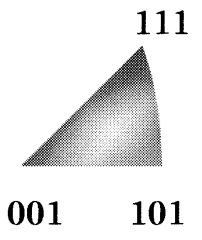

$1 \mathrm{~mm}$

Fig. 4. OIM orientation images of the crystallite lattice plane aligned with the surface (ND) of the same samples with Fig. 3 ; (a) $28 \mathrm{Al} / 1 \mathrm{Mo}$, (b) $28 \mathrm{Al} / 3 \mathrm{Mo}$, (c) $28 \mathrm{Al} / 5 \mathrm{Mo}$, (d) $28 \mathrm{Al} / 5 \mathrm{Cr}$, (e) $28 \mathrm{Al} / 10 \mathrm{Cr}$ and (f) $28 \mathrm{Al} / 15 \mathrm{Cr}$.

(a)

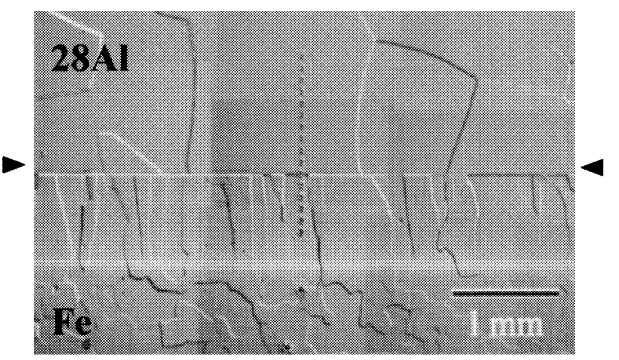

(b)

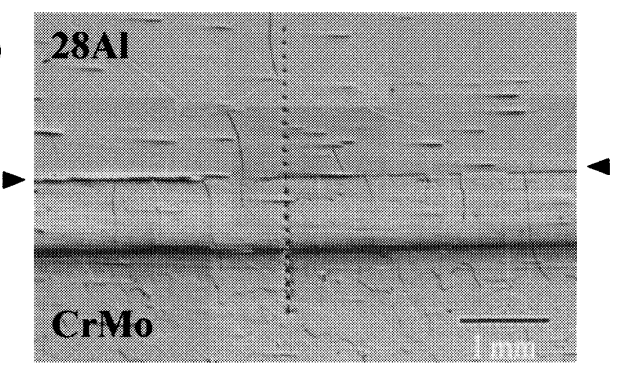

(c)

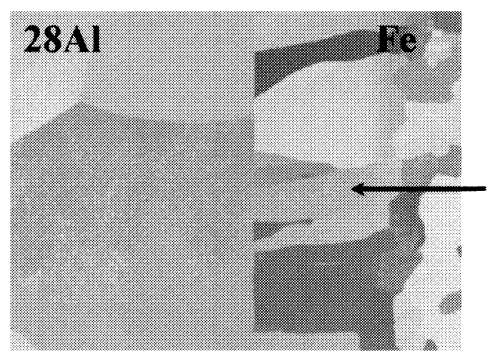

(d)

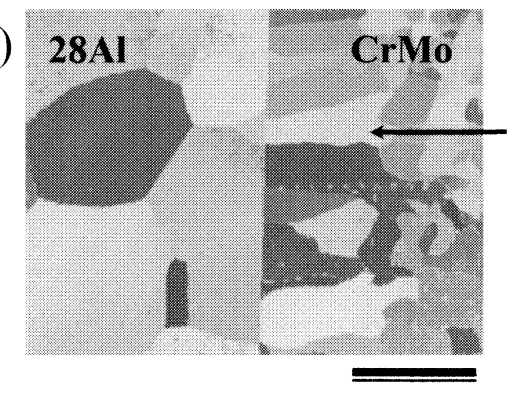

$1 \mathrm{~mm}$

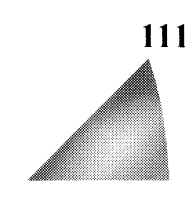

$001 \quad 101$

Fig. 5. Optical microscopy images from the cross section close to the geometric center of samples; (a) $28 \mathrm{Al} / \mathrm{Fe}$ and (b) $28 \mathrm{Al} / \mathrm{CrMo}$, and OIM orientation images for ND: (c) $28 \mathrm{Al} / \mathrm{Fe}$ and (d) $28 \mathrm{Al} / \mathrm{CrMo}$.

average values of the lengths and widths of columnar grains (described as $\langle\mathrm{L}\rangle$ and $\langle\mathrm{W}\rangle$ in Table 2) were derived as the average of all grains in the observed area (about $10 \times 5$ $\mathrm{mm}^{2}$ ), and the standard deviation of these values is inserted in the table. It is recognized that $\langle\mathrm{W}\rangle$ is small in $28 \mathrm{Al} / 1 \mathrm{Mo}$ and $28 \mathrm{Al} / \mathrm{Fe}$ compared with $28 \mathrm{Al} / 5 \mathrm{Cr}$ and $28 \mathrm{Al} / 10 \mathrm{Cr}$, whereas $\langle\mathrm{L}\rangle$ is similar among all samples. Two assumptions to explain the difference of the width could be accepted. The first one assumes that the coalescence of neighboring grains in the columnar microstructure progresses frequently in $28 \mathrm{Al} / 5 \mathrm{Cr}$ and $28 \mathrm{Al} / 10 \mathrm{Cr}$, while it is suppressed in $28 \mathrm{Al} /$ $1 \mathrm{Mo}$ and $28 \mathrm{Al} / \mathrm{Fe}$. This implies that the orientations of nuclei in $28 \mathrm{Al} / 5 \mathrm{Cr}$ and $28 \mathrm{Al} / 10 \mathrm{Cr}$ are nearly identical to each other so that grain coalescence takes place easily. The second one assumes that the nucleation sites at the joint interface are numerous in $28 \mathrm{Al} / 1 \mathrm{Mo}$ and $28 \mathrm{Al} / \mathrm{Fe}$ compared with those in $28 \mathrm{Al} / 5 \mathrm{Cr}$ and $28 \mathrm{Al} / 10 \mathrm{Cr}$. From comparison of the solubility limits of molybdenum and chromium in 
gamma iron, it is expected that longer time is necessary to cause gamma to alpha transformation in $28 \mathrm{Al} / 5 \mathrm{Cr}$ and $28 \mathrm{Al} / 10 \mathrm{Cr}$ than $28 \mathrm{Al} / 1 \mathrm{Mo}$ and $28 \mathrm{Al} / \mathrm{Fe}$. This indicates that gamma grain coarsening prior to transformation from gamma to alpha is prominent in $28 \mathrm{Al} / 5 \mathrm{Cr}$ and $28 \mathrm{Al} / 10 \mathrm{Cr}$, influencing the number of nucleation sites at joint interface. In order to refine microstructure of steel, transformation from fine gamma has been widely accepted, because fine gamma grains provide larger amounts of nucleation sites of alpha. ${ }^{11,12)}$ The wide columnar grains in $28 \mathrm{Al} / 5 \mathrm{Cr}$ and $28 \mathrm{Al} / 10 \mathrm{Cr}$ could be attributable to the second assumption. Furthermore, it is interesting to note that $\langle\mathrm{W}\rangle$ in $28 \mathrm{Al} /$ CrMo is between those in $28 \mathrm{Al} / 5 \mathrm{Cr}$ and $28 \mathrm{Al} / 1 \mathrm{Mo}$, sug-

Table 2. Values of the average length of columnar grains $\langle\mathrm{L}\rangle$, average width of columnar grains $\langle\mathrm{W}\rangle$ and average aspect ratio $\langle\mathrm{R}\rangle$ characterizing the morphology of columnar microstructure. Standard deviation of $\langle\mathrm{L}\rangle$ and $\langle\mathrm{W}\rangle$ is in parentheses.

\begin{tabular}{c|c|c|c}
\hline Couples & $\begin{array}{c}<\mathrm{L}> \\
/ \mu \mathrm{m}\end{array}$ & $\begin{array}{c}<\mathrm{W}> \\
/ \mu \mathrm{m}\end{array}$ & $<\mathrm{R}>$ \\
\hline $28 \mathrm{Al} / 1 \mathrm{Mo}$ & $1071(459)$ & $105(58)$ & $10.2(4.9)$ \\
\hline $28 \mathrm{Al} / 5 \mathrm{Cr}$ & $1095(422)$ & $225(104)$ & $4.9(2.5)$ \\
\hline $28 \mathrm{Al} / 10 \mathrm{Cr}$ & $1174(370)$ & $249(162)$ & $4.7(2.3)$ \\
\hline $28 \mathrm{Al} / \mathrm{CrMo}$ & $881(188)$ & $183(97)$ & $4.8(1.4)$ \\
\hline $28 \mathrm{Al} / \mathrm{Fe}$ & $1118(282)$ & $139(85)$ & $6.2(4.2)$ \\
\hline
\end{tabular}

(a)

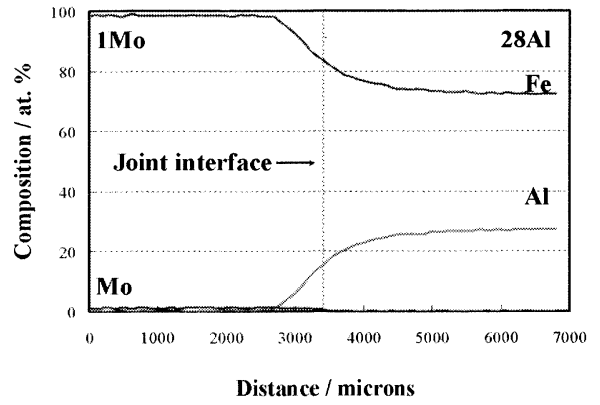

(b)

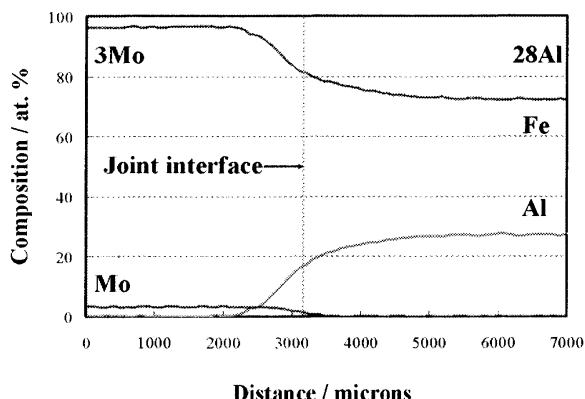

(c)

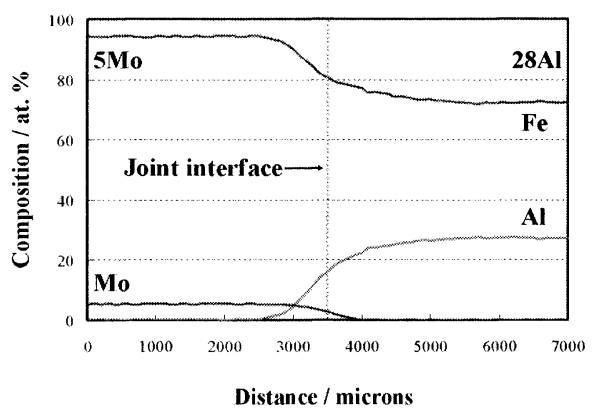

gesting that an addition of $0.5 \mathrm{wt} \%$ molybdenum to $\mathrm{Fe}-5 \mathrm{Cr}$ alloy influences columnar microstructure evolution behavior. It is expected that an addition of $0.5 \mathrm{wt} \%$ molybdenum to $\mathrm{Fe}-5 \mathrm{Cr}$ alloy decreases the solubility limit in ferrite.

\subsection{Concentration Profile}

Figure 6 shows the concentration profiles in the columnar grain indicated by an arrow in Fig. 4 for $28 \mathrm{Al} / 1 \mathrm{Mo}$, $28 \mathrm{Al} / 5 \mathrm{Cr}$, and $28 \mathrm{Al} / 10 \mathrm{Cr}$ and along the centerline in Fig. 4 for $28 \mathrm{Al} / 3 \mathrm{Mo}, 28 \mathrm{Al} / 5 \mathrm{Mo}$, and $28 \mathrm{Al} / 15 \mathrm{Cr}$. It reveals continuous changes of the concentrations of the constitutional elements and absence of intermediate phases near the joint interfaces. Aluminum diffuses into the steel from iron aluminide with about $1 \mathrm{~mm}$, while the extents of chromium or molybdenum diffusion are relatively moderate. The length of the columnar grains and two values (AD and $\mathrm{ED})$ related to aluminum diffusion derived from the concentration profiles in the grains are summarized in Table 3. Here, AD is defined as the distance between the joint interface and the position where the aluminum concentration falls to zero. It is recognized that the columnar grain lengths are longer than $\mathrm{AD}$ in all these referred grains. The aluminum solubility limit in alpha phase at $1323 \mathrm{~K}$ for $\mathrm{Fe}-\mathrm{Al}-\mathrm{Cr}$ ternary alloy is estimated to be about 7.0 at\% (Fig. 7). ${ }^{13)}$ When the aluminum concentration in CrMo steel is lower than 7.0 at $\%$, transformation from alfa to gamma should occur. The position of 7.0 at $\%$ aluminum composition is derived

(d)

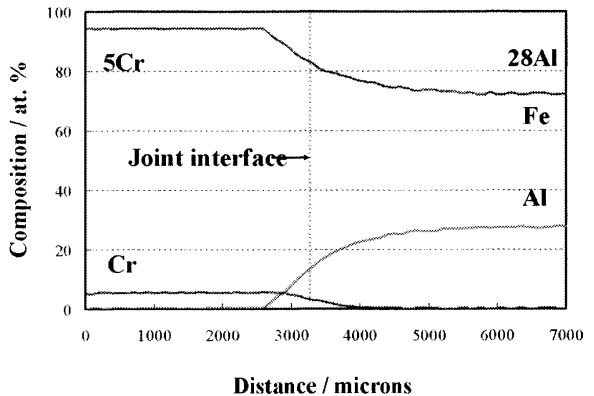

(e)

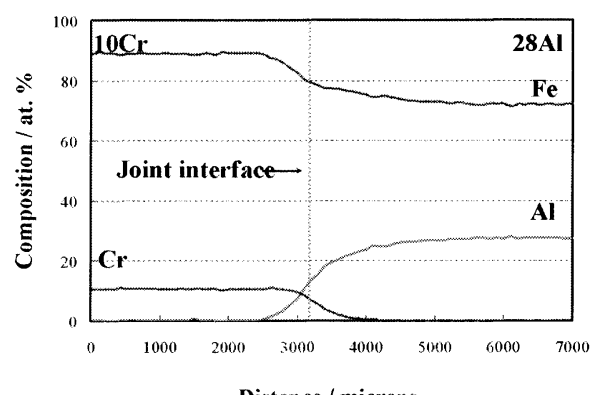

(f)

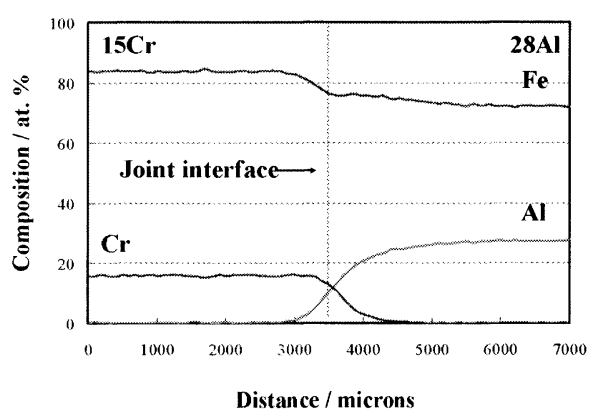

Fig. 6. Concentration profiles in the specified grain indicated by arrow or the along the center line in Fig. 4; (a) 28Al/ $1 \mathrm{Mo}$, (b) $28 \mathrm{Al} / 3 \mathrm{Mo}$, (c) $28 \mathrm{Al} / 5 \mathrm{Mo}$, (d) $28 \mathrm{Al} / 5 \mathrm{Cr}$, (e) $28 \mathrm{Al} / 10 \mathrm{Cr}$ and (f) $28 \mathrm{Al} / 15 \mathrm{Cr}$. 
Table 3. Values of the length, aluminum diffusion distance, and ED of specified columnar grain and interdiffusion coefficient.

\begin{tabular}{c|c|c|c|c}
\hline Couples & $\begin{array}{c}\text { Length of } \\
\text { columnar grain } \\
/ \mu \mathrm{m}\end{array}$ & $\mathrm{AD} / \mu \mathrm{m}$ & $\mathrm{ED} / \mu \mathrm{m}$ & $\begin{array}{c}\text { Interdiffusion } \\
\text { coefficient } \\
\times 10^{-12} \mathrm{~m}^{2} \cdot \mathrm{s}^{-1}\end{array}$ \\
\hline $28 \mathrm{Al} / 1 \mathrm{Mo}$ & 1421 & 950 & - & 0.793 \\
\hline $28 \mathrm{~A} 1 / 5 \mathrm{Cr}$ & 1395 & 950 & 581 & 0.889 \\
\hline $28 \mathrm{Al} / 10 \mathrm{Cr}$ & 1342 & 900 & 608 & 0.788 \\
\hline $28 \mathrm{Al} / \mathrm{CrMo}$ & 1037 & 700 & - & 0.560 \\
\hline $28 \mathrm{Al} / \mathrm{Fe}$ & 1170 & 850 & 762 & 0.975 \\
\hline
\end{tabular}

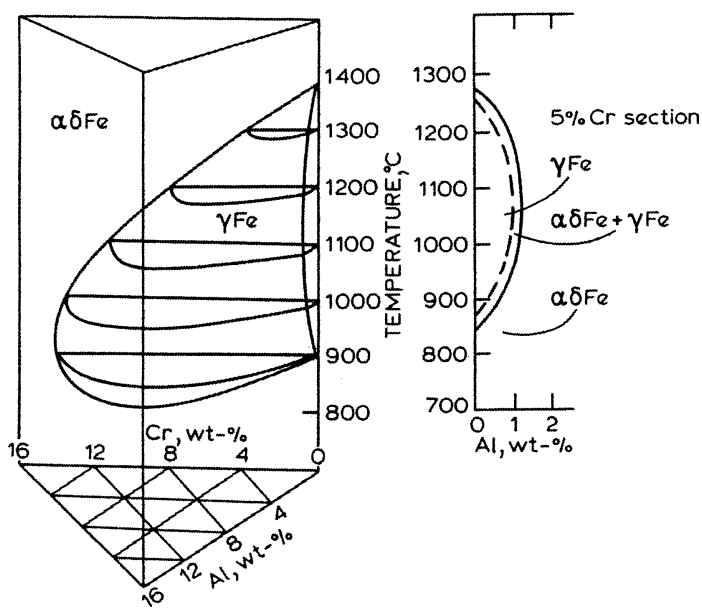

Fig. 7. A partial phase diagram of $\mathrm{Fe}-\mathrm{Al}-\mathrm{Cr}$ system. ${ }^{13)}$

from the concentration profile (Fig. 6), and another distance between the joint interface and the above position is introduced as ED in Table 3. ED was calculated for $28 \mathrm{Al} / x \mathrm{Cr}$ $(x=5,10)$ and $28 \mathrm{Al} / \mathrm{Fe}$ couples. ED could not be calculated for $28 \mathrm{Al} / x \mathrm{Mo}(x=1)$ and $28 \mathrm{Al} / \mathrm{CrMo}$ couples, because phase diagrams for $\mathrm{Fe}-\mathrm{Al}-\mathrm{Mo}$ and $\mathrm{Fe}-\mathrm{Al}-\mathrm{Cr}-\mathrm{Mo}$ have not been reported. It is recognized again that the columnar grain lengths are longer than ED in all these referred grains. These results suggest that columnar grain evolves further than expected from chemical composition analyses.

Interdiffusion coefficients were derived from the concentration profiles by using the Boltzmann-Matano method, ${ }^{14)}$ and those at the Matano interface are incorporated in Table 3. Alloying effect on diffusion was done with the aid of a plot of interdiffusion coefficient at the Matano interface against the content of alloying element. Figure 8 illustrates dependence of interdiffusion coefficients on the content of alloying element for investigated couples. This plot suggests that there exists a negative correlation between an addition of alloying element and interdiffusion coefficient, and its decrease rate is relatively high for molybdenum alloyed steel compared with chromium alloyed steel.

In the proposed model, the columnar microstructure evolution proceeds in the presence of aluminum concentration gradient, whereas the relation between the length of columnar grains and the distribution of aluminum has not been discussed. It is notable that the length of columnar grains of $28 \mathrm{Al} / 5 \mathrm{Cr}$ and $28 \mathrm{Al} / 10 \mathrm{Cr}$ is longer than that of $28 \mathrm{Al} / 1 \mathrm{Mo}$ as shown in Table 2. Furthermore, the interdiffusion coeffi-

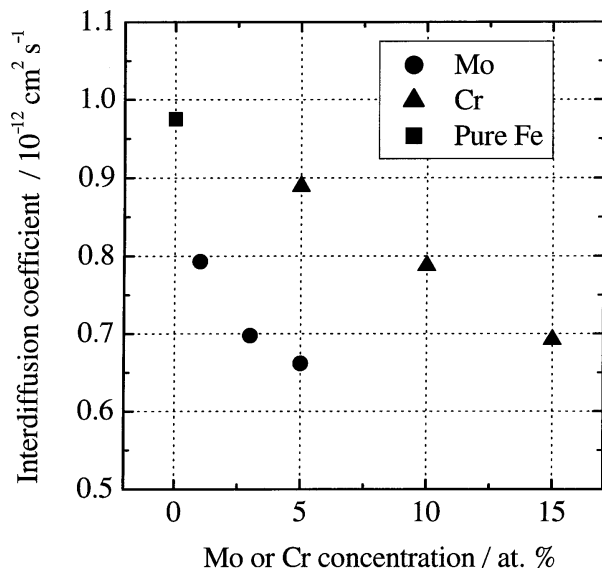

Fig. 8. Dependence of interdiffusion coefficients on the content of alloying element of Mo and $\mathrm{Cr}$.

cient at the Matano interface of $28 \mathrm{Al} / 5 \mathrm{Cr}$ and $28 \mathrm{Al} / 10 \mathrm{Cr}$ is larger than that of $28 \mathrm{Al} / 1 \mathrm{Mo}$. These imply that the length of columnar grains increases with the interdiffusion coefficient, although the length of columnar grains is not concordant with $\mathrm{AD}$ or ED. The present result that the length of columnar grains is longer than AD or ED implies that nucleated alpha grains grow in areas of lower aluminum concentrations than the solubility limit or free from aluminum. It is concluded that the gradient of aluminum concentration determines the growth direction of nucleated alpha grains, but not the absolute length of evolved grain from the present result using $28 \mathrm{Al} / \mathrm{Fe}-\mathrm{X}(\mathrm{X}=\mathrm{Cr}, \mathrm{Mo}), 28 \mathrm{Al} / \mathrm{Fe}$ and $28 \mathrm{Al} / \mathrm{CrMo}$, and the previous result using $6 \mathrm{Cr} / \mathrm{Fe}$ and $6 \mathrm{Cr} / \mathrm{CrMo}$. In a recent study using the couple of iron aluminum alloy and carbon steel, the length of columnar grains agrees with $\mathrm{AD},{ }^{15)}$ which differs from the present and previous results. ${ }^{7,8)}$ The role of alloy chemistry on the microstructure formation needs to be clarified in the light of phase stability. A further detailed understanding of the relationship between the length of columnar grains and aluminum diffusion is required.

\subsection{Orientation Change of Columnar Grains during Grain Growth}

Figure 9 displays a variation of ND orientation difference between the interface vicinity $(10 \mu \mathrm{m}$ apart from the joint interface) and individual analyzed points in the columnar grains, indicated by the arrows in Fig. 4, against the distance from the interface for $28 \mathrm{Al} / 1 \mathrm{Mo}$ and $28 \mathrm{Al} / 5 \mathrm{Cr}$. The deviation from the orientation of interface vicinity in both samples lie within a small angular spread, and the variation for $28 \mathrm{Al} / 1 \mathrm{Mo}$ is relatively small compared with that for $28 \mathrm{Al} / 5 \mathrm{Cr}$. This is generally observed for other columnar grains in the same samples, suggesting that a columnar grain develops with maintaining its nucleus orientation.

Detailed investigation for the same grain was conducted by dividing the columnar grain into several parts to consider growth behavior. In the present study, an image quality value obtained by using EBSP technique is introduced to explain the differences between the samples. ${ }^{16)}$ Image quality value corresponds to perfection of crystal lattice, and is reduced by any distortion in crystal lattice, including an induced strain through transformation. As a consequence, a low image quality value means that the crystal lattice stores 


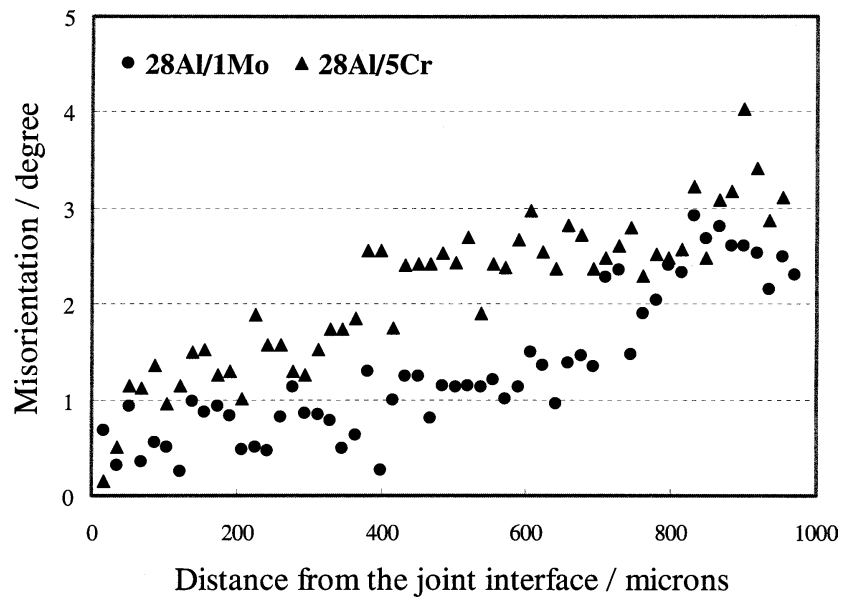

Fig. 9. Variation of ND orientation difference between the interface vicinity (10 $\mu \mathrm{m}$ apart from joint interface) and individual analyzed point in the specified columnar grain indicated by arrow in Fig. 4 against distance from the interface for $28 \mathrm{Al} / 1 \mathrm{Mo}$ and $28 \mathrm{Al} / 5 \mathrm{Cr}$.

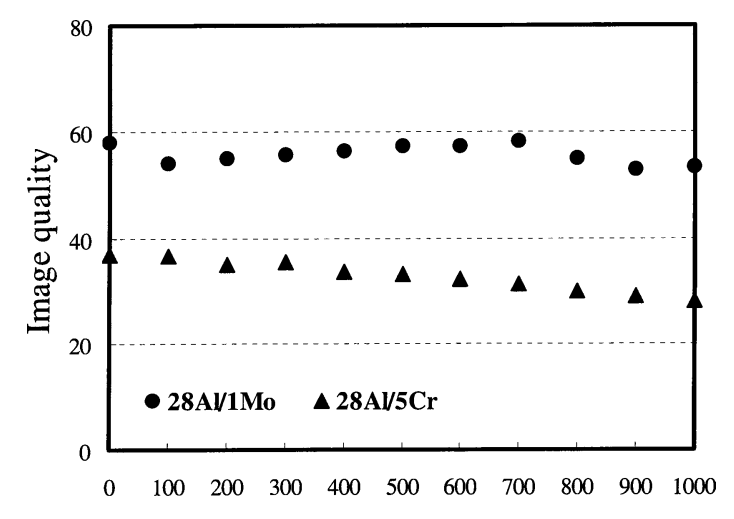

Distance from the joint interface / microns

Fig. 10. Plots of image quality of EBSPs as a function of distance from the interface for $28 \mathrm{Al} / 1 \mathrm{Mo}$ and $28 \mathrm{Al} / 5 \mathrm{Cr}$.

a higher strain. This factor has been used for microstructure characterizations such as the stored energy for recrystallization, ${ }^{17)}$ strain distribution, ${ }^{18)}$ and orientation distinction between phases. ${ }^{19)}$ It should be noted that its value depends on the sample preparation procedure and the measuring conditions in EBSP experiment, and direct comparison of its absolute values between different experiments using different conditions is insignificant. In the present study, all the samples were prepared in the same manner and EBSPs were obtained in the same condition. Therefore, a relative measure of changes in residual strain with the distance from the joint interface in columnar grains can be evaluated by a comparison of the average image quality value. Image quality (IQ) of EBSPs is plotted in Fig. 10 as a function of the distance from the joint interface. In $28 \mathrm{Al} / 1 \mathrm{Mo}$, IQ is almost constant with high values independent of the distance from the interface, while it is low and decreases with the distance from the interface in $28 \mathrm{Al} / 5 \mathrm{Cr}$. This is recognized in other grains of $28 \mathrm{Al} / 1 \mathrm{Mo}$ and $28 \mathrm{Al} / 5 \mathrm{Cr}$, although the absolute value of IQ varies in each grain. Difference in the behaviors of the transformation and grain growth between them could explain the above. In the case of $28 \mathrm{Al} / 1 \mathrm{Mo}$, the transformation occurs in the early stage of the diffusion bonding, be- cause the amount of aluminum required to cause the transformation from gamma to alpha is low and the corresponding diffusion time is short. When alpha phase is stabilized by aluminum diffusion in steel, alpha nucleation occurs and the induced strain by transformation remains scarcely in the columnar grains. On the other hand, a large amount of aluminum is required to cause the transformation from gamma to alpha in $28 \mathrm{Al} / 5 \mathrm{Cr}$ and $28 \mathrm{Al} / 10 \mathrm{Cr}$, because the solubility limit of chromium in gamma is high. Long time annealing to supply aluminum for the transformation results in gamma grain coarsening before the transformation. Coarsened gamma grains transform from the joint interface, which is considered sluggish compared with $28 \mathrm{Al} / 1 \mathrm{Mo}$. This difference in the transformation kinetics between $28 \mathrm{Al} / 1 \mathrm{Mo}$ and $28 \mathrm{Al} / 5 \mathrm{Cr}$ might influence the residual strain and the quality of EBSPs. The investigation for the validity of this assumption is in progress by using micro-area X-ray diffraction analysis.

\section{Conclusions}

The mechanism of columnar microstructure evolution in iron aluminide and steel composites was investigated focusing on the effect of alloying elements. The principal conclusions are summarized as follows.

(1) Columnar microstructure develops in the steel side of diffusion couples of $28 \mathrm{Al} / \mathrm{Fe}-\mathrm{X}(\mathrm{X}=\mathrm{Cr}, \mathrm{Mo})$, when the steel composition is in the gamma phase at the bonding temperature. This is consistent with the proposed model for the columnar microstructure evolution.

(2) The length of columnar grains in the steel side of the couple is longer than the distances expected by chemical composition analysis. The gradient of aluminum concentration determines the growth direction of nucleated grains, but does not influence the absolute length of the evolved grains.

(3) The interdiffusion coefficient at the Matano interface for the couple of chromium alloyed steel is higher than that for the couple of molybdenum alloyed steel.

(4) Based on the kinetics of microstructure formation during diffusion bonding, it is speculated that the residual strain through transformation depends on alloying elements of $\mathrm{X}$ in steel, which is closely related to $\mathrm{Fe}-\mathrm{Al}-\mathrm{X}$ ternary phase diagrams.

\section{Acknowledgement}

The authors gratefully acknowledge Dr. T. Ikeda and Prof. H. Nakajima (Institute of Scientific and Industrial Research, Osaka University) for helpful comments to analyze the interdiffusion coefficient. The assistance of Dr. K. Takada, Mr. H. Konno, Mr. T. Ashino and Mr. F. Sakamoto with chemical analysis is also gratefully acknowledged. N.M. would like to thank The Iron and Steel Institute of Japan to support this study financially.

\section{REFERENCES}

1) W. Gao, Z. Li, Z. Wu, S. Li and Y. He: Intermetallics, 10 (2002), 263.

2) A. Mignone, S. Frangini, A.L.A. Barbera and O. Tassa: Corros. Sci., 40 (1998), 1331.

3) K. Natesan: Mater. Sci. Eng., A258 (1998), 126.

4) I. Rommerskirchen, B. Eltester and H.J. Grabke: Mat. Corros., 47 
ISIJ International, Vol. 44 (2004), No. 5

(1996), 646.

5) K. M. N. Prasanna, A.S. Khanna, R. Chandra and W.J. Quadakkers: Oxid. Met., 46 (1996), 465.

6) P. Tomaszewicz and G. R. Wallwork: Oxid. Met., 19 (1983), 165.

7) N. Masahashi, N. Kondo and S. Hanada: Ann. Chim. Sci. Mater, 27 (2002), S231.

8) N. Masahashi, S. Watanabe, N. Nomura, S. Semboshi and S. Hanada: Proc. of Int. Symp. on Intermetallics and Advanced Metallic Materials, TMS, Warrendale, PA, (2003), to be published.

9) V. Raghavan: Phase Diagrams of Ternary Iron Alloys, The Indian Institute of Metals, Calcutta, (1989), 10

10) T. B. Massalski: Binary Alloys Phase Diagrams, American Society for Metals, Ohio, (1986).

11) T. Maki: Tetsu-to-Hagané, 81 (1995), N547 (in Japanese)

12) R. Kasparr, U. Lotter, C. Biegus: Steel Res., 65 (1994), 242.
13) G. V. Raynor and V. G. Rivlin: Phase Equilibria in Iron Ternary Alloys, The Institute of Metals, London, (1988), 87.

14) J. S. Kirkaldy, J. E. Lane and G. R. Mason: Can. J. Phys., 41 (1963), 2174 .

15) N. Masahashi, K. Komatsu, S. Watanabe and S. Hanada: Mater. Sci. Eng., (2004), submitted.

16) OIM Analysis User Manual, TexSEM Laboratories, Draper, Utah, (1997).

17) J.-T. Park and J. A. Szpunar: Acta Mater., 51 (2003), 3037.

18) S. T. Wardle, L. S. Lin, A. Cetel and B. L. Adams: Proc. of 52nd Annual Meeting of the Microscopy Society of America, ed. by G. W. Bailey and A. J. Garratt-Reed, San Francisco Press, San Francisco, (1994), 680.

19) M. De Meyer, L. Kestens and B. C. De Cooman: Mater. Sci. Technol., 17 (2001), 1353 